\title{
Ocena przydatności metod ultradźwiękowej i indukcji elektromagnetycznej do identyfikacji właściwości fibropiaskobetonu
}

\author{
Usefulness assessment of ultrasound \\ and electromagnetic induction methods \\ for the identification of steel fibre reinforced \\ fine aggregate concrete properties
}

\section{Streszczenie}

W artykule dokonano oceny przydatności metod nieniszczących, ultradźwiękowej oraz indukcji elektromagnetycznej, do określania właściwości fibropiaskobetonu. Sformułowano równania regresji opisujące właściwości takiego kompozytu w zależności od prędkości propagacji fali ultradźwiękowej oraz natężenia indukowanego prądu w zbrojeniu rozproszonym. Równania poddano weryfikacji praktycznej przeprowadzając badania kompozytu wykonanego w warunkach przemysłowych. Uzyskano zadowalającą zgodność wyników otrzymanych na drodze eksperymentalnej i analitycznej.

\section{Abstract}

In the article the usefulness of two methods for the determination of fine aggregate steel fibre reinforced concrete properties was assessed. The regression equations were formulated. The equations were describing the properties of such composite depending on the speed of the ultrasound wave propagation and intensity of induced in steel fibres electric current. The equations were verified in practice by testing composite made under industrial conditions. The compatibility of the results obtained experimentally and analytically was satisfactory.

\section{Cel i znaczenie badań}

Fibropiaskobetony $z$ uwagi na zadowalające właściwości mechaniczno-fizyczne znajdują coraz szersze zastosowanie $w$ przemyśle budowlanym. Stosowane są między innymi do wytwarzania konstrukcyjnych elementów cienkościennych, cienkich płyt okładzin budynków, posadzek przemysłowych, elementów cienkich powłok, przekryć budynków, do budowy nawierzchni

Dr hab. inż. Wiesława Głodkowska, prof. PK, mgr inż. Janusz Kobaka - Politechnika Koszalińska. mostów, tuneli, wzmacniania wyrobisk kopalnianych, wreszcie do wznoszenia obiektów obciążonych dynamiczne [1].

Przy tak szerokim spektrum zastosowań fibropiaskobetonu odczuwa się brak szybkiej, bezinwazyjnej i skutecznej metody oceny jego właściwości po wbudowaniu w konstrukcję. Ponadto stosowane metody oceny właściwości fibropiaskobetonu na normatywwych próbkach nie pozwalają na dokładną ocenę rozkładu wartości jego cech w elementach i konstrukcji.

Celem badań doświadczalnych i analiz teoretycznych była więc ocena przydatności dwóch metod nieniszczących, ultradźwiękowej i indukcji elektromagnetycznej, do identyfikacji podstawowych właściwości 
kompozytu drobnokruszywowego o różnej zawartości włókien stalowych oraz wskazanie sposobu określania właściwości takiego kompozytu w konstrukcji.

\section{Materiały i elementy próbne}

Do wykonania elementów próbnych zastosowano piasek pochodzenia polodowcowego pozyskany po procesie hydroklasyfikacji z regionu Pomorza Zachodniego [2], cement portlandzki CEM II/A-V 42,5R, pył krzemionkowy oraz superplastyfikator zawierający pucolanę. Zbrojenie rozproszone stanowiły włókna stalowe o kształcie haczykowatym i smukłości $\lambda=1 / d$ $=62,5(1=50 \mathrm{~mm}, d=0,8 \mathrm{~mm})$. Skład matrycy zmodyfikowano przez zastosowanie dodatku pyłów krzemionkowych oraz superplastyfikatora pozwalającego na uzyskanie stosunku w/c=0,38. Jako zmienną składową kompozytu przyjęto zawartość włókien stalowych $(V)$, które dozowano co 0,5\% w stosunku do objętości kompozytu, do 2,5\%. Włókna w mieszance kompozytu rozmieszczone były w sposób przypadkowy. Badania wytrzymałości na ściskanie $\left(f_{c, \text { cube }}\right)$, gęstości pozornej $(\rho)$ oraz dynamicznego modułu sprężystości $\left(E_{d}\right)$ kompozytu drobnokruszywowego wykonano na próbkach sześciennych o boku $150 \mathrm{~mm}$. Skurcz utwardzania $\left(\varepsilon_{\mathrm{s}}\right)$ oznaczano na belkach o wymiarach 100x100x400 mm. Odporność na ścieranie (S) kompozytu zbadano na próbkach sześciennych o boku $71 \mathrm{~mm}$.

Liczbę próbek, niezbędną do określenia średniej wartości statystycznej badanej cechy, wyznaczono na podstawie statystycznej analizy wyników badań wstępnych za pomocą rozkładu t-Studenta przy tolerancji $v=10 \%$ i poziomie istotności $\alpha=0,10$.

\section{Metodyka badań}

Wytrzymałość $f_{c, \text { cube }}$ określono wg PN-EN 12390-3. Gęstość pozorną $\rho$ oznaczono zgodnie z zaleceniami PN-EN 12390-7, a dynamiczny moduł sprężystości $E_{d}$ zdefiniowany został na podstawie analizy prędkości przebiegu fali ultradźwiękowej wg [3, 4]. Odporność na ścieranie kompozytu $S$ określono wg zasad przedstawionych w PN-84/B-04111. Przebieg skurczu $\varepsilon_{s}$ kompozytu w czasie t wyznaczono zgodnie z instrukcją ITB 194 Badania cech mechanicznych betonu na próbkach wykonanych w formach. Badania nieniszczące przeprowadzono dwoma metodami przy użyciu detektora zbrojenia Femetr $2 E 2$ oraz betonoskopu ultradźwiękowegoo częstotliwości pomiarowej $54 \mathrm{kHz}$. Pierwsza z metod oparta na indukcji elektromagnetycznej została użyta do oszacowania w badanym kompozycie zawartości zbrojenia rozproszonego oraz wyznaczenia zależności wybranych jego cech od natężenia indukowanego prądu $I$. Drugą z metod zastosowano do określenia zależności cech kompozytu od prędkości fali ultradźwiękowej $V[5 \div 7]$. Badania nieniszczące wykonano na próbkach przeznaczonych do badań doraźnych oraz reologicznych po ustabilizowaniu odkształceń wywołanych skurczem.

\section{Wyniki badań i ich analiza}

Badania nieniszczące, towarzyszące wszystkim niszczącym badaniom doraźnym, pozwoliły na określenie ich wzajemnych relacji. Na rysunku 1 przedstawiono zależności wytrzymałości $f_{c, c u b e}$, gęstości $\rho$, modułu $E_{d}$ i ścieralności $S$ od natężenia prądu $I$. Wytrzymałość $f_{c \text { cube }}$ i gęstość $\rho$ zwiększają się wraz ze wzrostem natężenia prądu indukcyjnego $I$, nie jest to jednak zależność prostoliniowa. Dla dużych wartości natężenia prądu ( $>3 \mathrm{~mA}$ ), co odpowiada zawartości zbrojenia rozproszonego $V_{f}>1,5 \%$ w stosunku do objętości kompozytu, przyrost wytrzymałości $f_{c, c u b e}$ oraz gęstości $\rho$ jest niewielki. Wartość modułu $E_{d}$ rośnie wraz ze wzrostem natężenia prądu $I$, jednak powyżej wartości $I=2,9 \mathrm{~mA}$, co odpowiada $1,5 \%$ zbrojenia rozproszonego, wartość modułu maleje (rys. 1c). Spowodowane jest to napowietrzeniem mieszanki kompozytu w trakcie mieszania przez dużą zawartość włókien [1]. Najmniejszą ścieralność kompozyt wykazuje przy natężeniu prądu $I=2,2 \mathrm{~mA}$ (rys. $1 \mathrm{~d}$ ). W przypadku skurczu $\varepsilon_{s}$ wzrostowi wartości natężenia prądu $I$, co odpowiada zwiększającej się zawartości włókien w kompozycie, towarzyszy ograniczenie odkształceń wywołanych skurczem.

Funkcje opisujące zależność wytrzymałości $f_{c, \text { cube- }}$ od zawartości włókien $V_{f}$ w kompozycie oraz od natężenia prądu $I$ (rys. 2 i 1a) mają podobny przebieg; wytrzymałość $f_{c, c u b e}$ wzrasta nieliniowo wraz z zawartością włókien $V_{f}$ i natężeniem prądu $I$. Wynika stąd zależność, że zawartość włókien w kompozycie do $V_{f}=1,5 \%$ wyraźnie wpływa na wzrost wytrzymałości $f_{c, \text { cube }}^{f}$. Powyżej tej zawartości włókien obserwuje się już nieznaczny przyrost wytrzymałości $f_{c, \text { cube }}$ kompozytu. Ponadto zgodność przebiegu funkcji pokazanych na rysunku 1a i 2 świadczy o możliwości zastosowania metody indukcji elektromagnetycznej do oceny zawartości zbrojenia rozproszonego w kompozycie. Podobną zależność uzyskano także dla pozostałych właściwości kompozytu.

Do opisu zależności wytrzymałości $f_{c, c u b e}$, gęstości $\rho$, a także modułu $E_{d}$ od prędkości fali $V$ użyto dwóch krzywych (rys. 3). W tych przypadkach analiza statystyczna wykazała, że wyniki badań nie należą do tej samej populacji. Z rysunku 3 wynika, że wraz ze wzrostem zawartości włókien do 1,5\% następuje znaczny przyrost wytrzymałości $f_{c, c u b e}$, gęstości $\rho$, modułu $E_{d}$ kompozytu oraz wzrost prędkości fali $V$.

Powyżej 1,5\% zawartości włókien w kompozycie obserwuje się już nieznaczny przyrost wytrzymałości 
a)

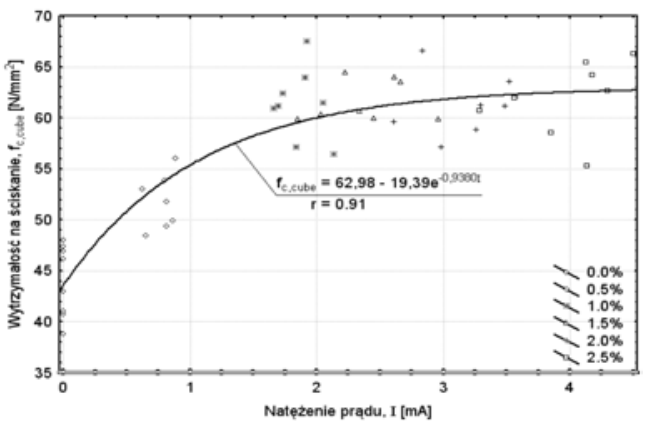

d)

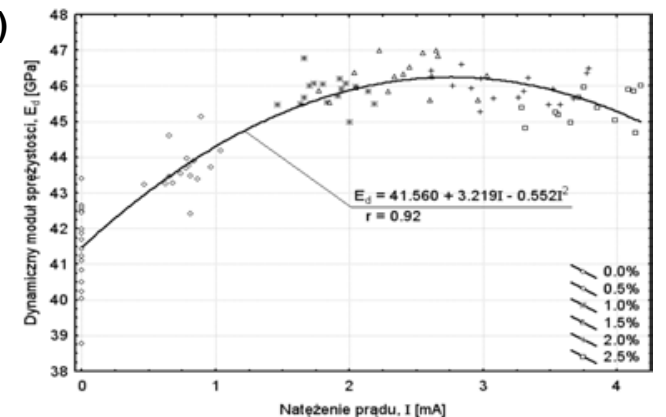

b)

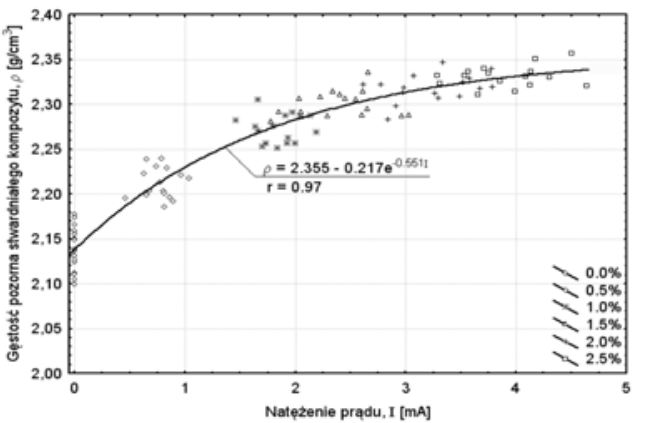

d)

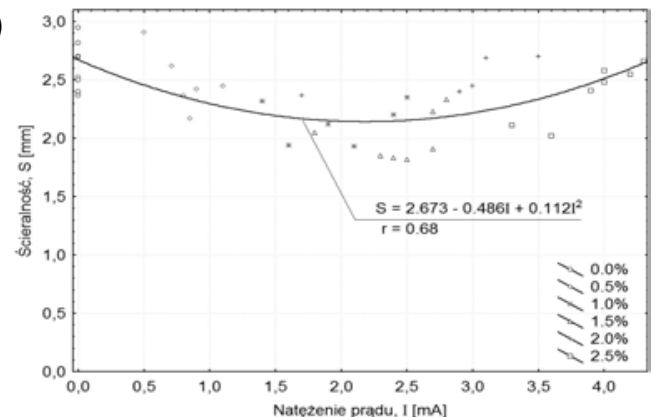

Rys. 1. Zależność: a) wytrzymałości $f_{c, c u b e}$, b) gęstości $\rho$, c) modułu $E_{d}$, d) ścieralności $S$ od natężenia prądu $I$ Fig. 1. Dependency: a) strength $f_{c, c u b e}$, b) the density $\rho$, c) the module $\mathrm{E}_{\mathrm{d}}$, d) abrasion $\mathrm{S}$ from current $I$

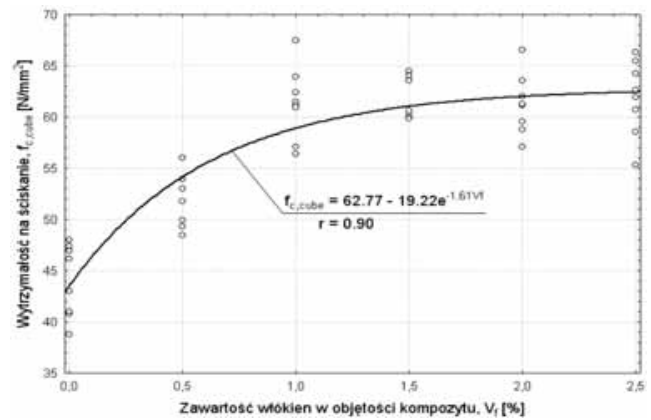

Rys. 2. Zależność wytrzymałości $f_{c \text {, cube }}$ badanego kompozytu od zawartości włókien $V_{f}$

Fig. 2. The relationship strength $f_{c, \text { cube }}$ test of composite fiber content $V_{f}$

a)

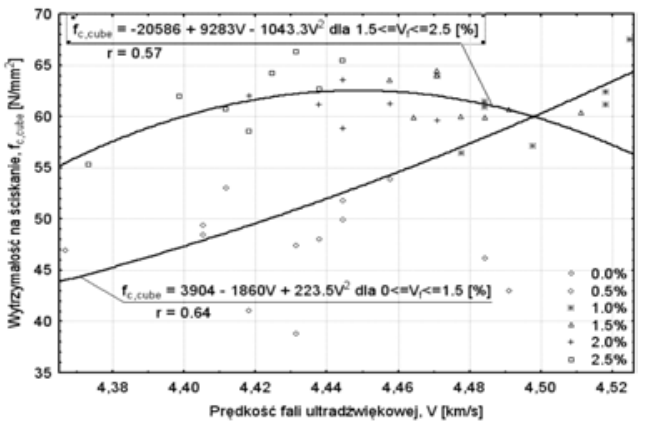

c)

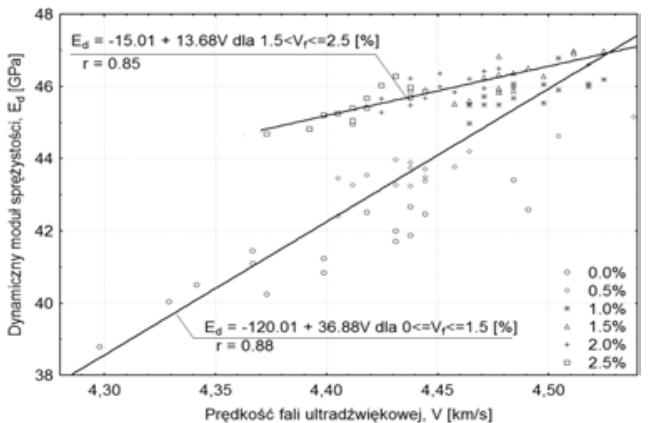

b)

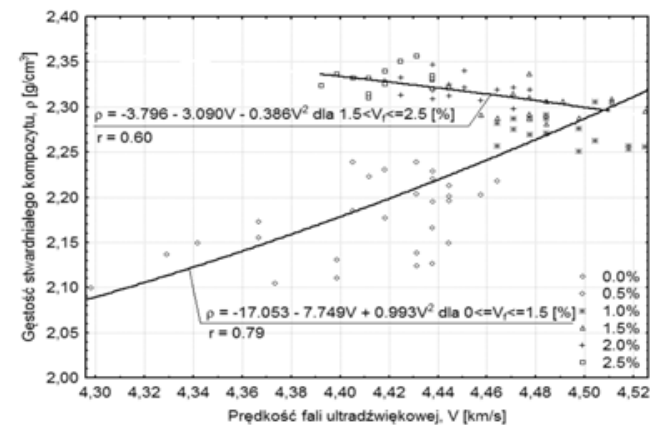

d)

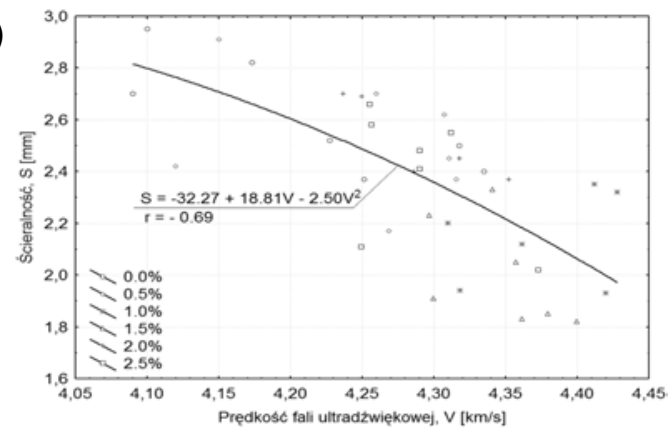

Rys. 3. Zależność: a) wytrzymałości $f_{c u e}$, b) gęstości $\rho$, c) modułu $E_{d}$, d) ścieralności $S$ badanego kompozytu od prędkości fali $V$

Fig. 3. Dependency: a) strength $f_{\text {cubbe }}$, b) a density $\rho$, c) the module $E_{d}$, d) abrasion of the composite test S-wave velocity $V$ 


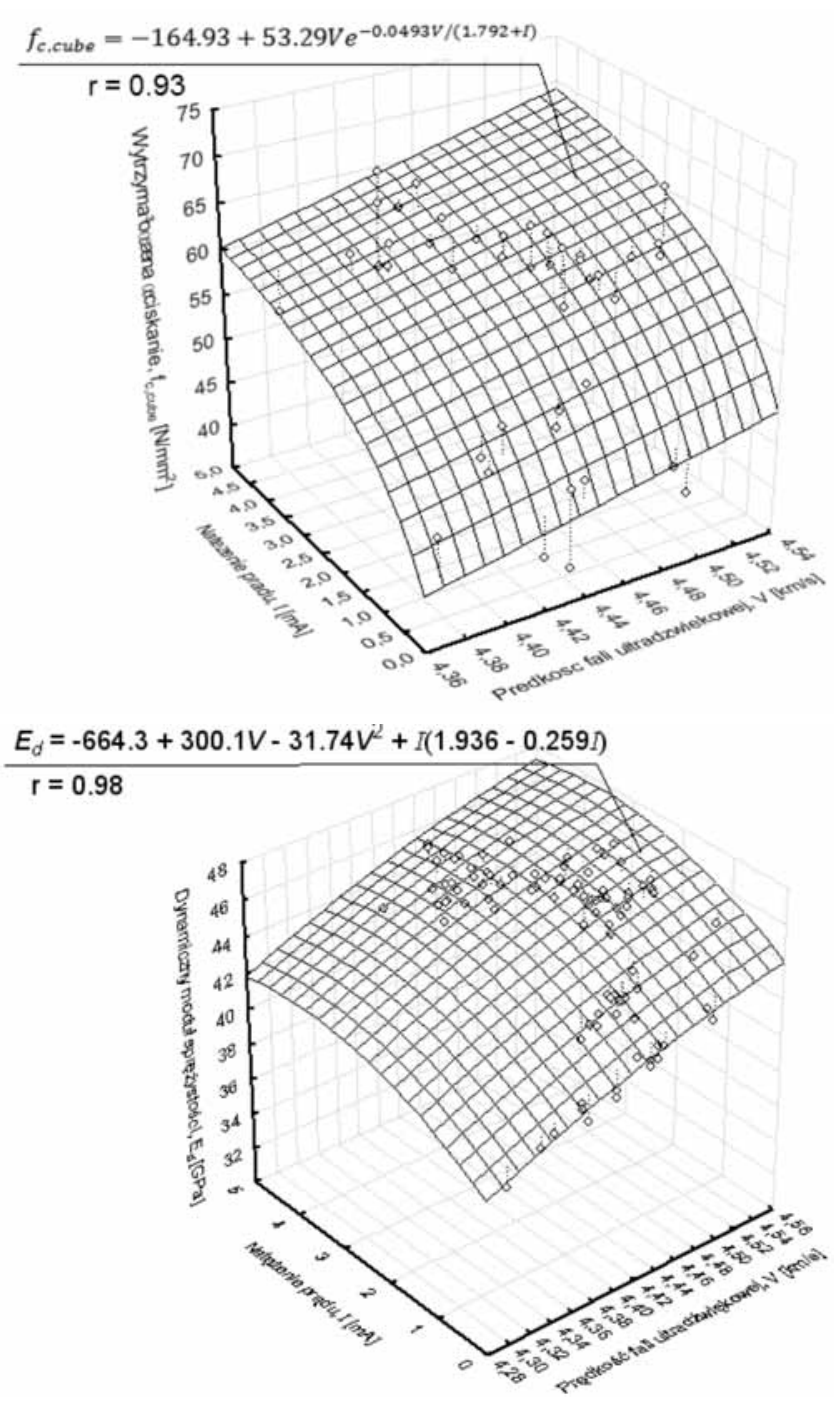

Rys. 4. Przykładowe zależności: a) wytrzymałości $f_{\text {cube }}$, b) modułu $E_{d}$ od prędkości fali $V$ oraz natężenia prądu I

Fig. 4. Sample based on: a) the strength $f_{\text {cube }}$, b) module of $E_{d}$ velocity $\mathrm{V}$ and current I

$f_{c, \text { cube }}$ i gęstości $\rho$ oraz spadek wartości modułu $E_{d}$ przy zmniejszającej się prędkości fali $V$. Stwierdzono ponadto, że ścieralność $S$ kompozytu zmniejsza się wraz ze wzrostem prędkości fali $V$.

Mając zdefiniowane zależności wybranych cech kompozytu od parametrów badań nieniszczących $(V \mathrm{i} I)$ w wyniku analizy korelacyjnej wyznaczono równania regresji y (cecha kompozytu) względem $x$ i z (natężenie prądu $I$ oraz prędkość fali $V$ ) - por. rys. 4 i równania $1 \div 6$.

$$
\begin{aligned}
& f_{c, \text { cube }}=-164,93+53,29 V e^{-0,0493 V /(1.792+l)}, \quad r=0,93 \\
& E_{d}=-664,3+300,1 V-31,74 V^{2}+I(1,936-0.259 I), r=0,98 \\
& S=-0,299 V+0,07 V^{2}+2,854 I-0,0527 I^{2}, r=0,77 \\
& \varepsilon_{s}=5,04\left(1-e^{-1,58 t^{0.49}}\right)-\frac{4,02}{e^{-0,00412 I}} \quad r=0,97 \\
& \rho=-26.03+12.83 V-1.45 V^{2}-0.210 e^{-0.0603 I} I, r=0,97
\end{aligned}
$$

Znając prędkość fali $V$ i natężenie prądu $I, z$ równań $1 \div 5$ można określić podstawowe właściwości fibropiaskobetonu objętego badaniami.

\section{Praktyczna weryfikacja}

Dla przeprowadzenia weryfikacji układu równań $(1 \div 5)$ wykonano w terenie trzy płyty fibropiaskobetonowe o różnej zawartości włókien stalowych: $0 \%, 1 \%$ i $2,5 \%$. Po ok. trzech latach przechowywania elementów próbnych w warunkach naturalnych poddano je badaniom nieniszczącym oraz niszczącym.

Na rysunku 5 zestawiono przykładowe wyniki badań cech fibropiaskobetonu.

Badania nieniszczące wykazały, że dla zawartości włókien stalowych: $0 \%, 1 \%$ i $2,5 \%$ średnie natężeni indukowanego prądu wyniosło odpowiednio: 0; 1,2 i 2,8 mA, natomiast średni czas przebiegu fali ultradźwiękowej: 4,48, 4,54 i 4,50 km/s.

Analiza uzyskanych wyników wykazała, że różnice między wartościami cech fibropiaskobetonu uzyskanymi z badań niszczących i obliczonymi dla odpowiednich wartości natężenia prądu $I$ oraz prędkości fali $V$ są statystycznie nieistotne i zawieraja się $\mathrm{w}$ przedziale od 0,6\% dla dynamicznego modułu sprężystości do 7,5\% w przypadku odporności na ścieranie. Na tej podstawie stwierdzono dobrą zgodność między eksperymentem a obliczeniami, co wskazuje na poprawność sformułowanych równań.
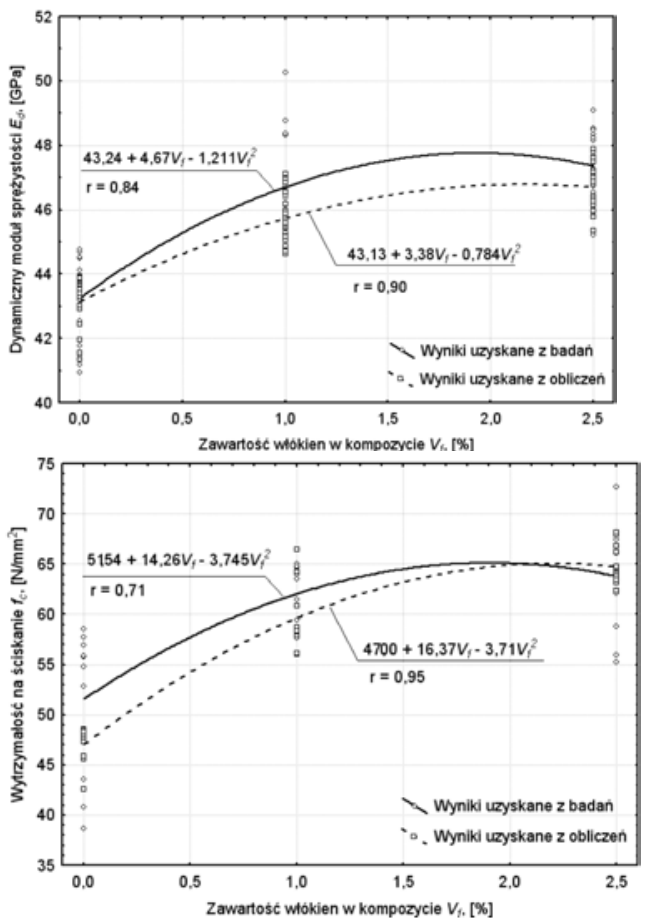

Rys. 5. Zestawienie eksperymentalnych i obliczeniowych wartości: a) dynamicznego modułu sprężystości $E_{d}$, b) wytrzymałości na ściskanie $f_{\text {cube }}$ fibropiaskobetonu

Fig. 5. Summary of experimental and calculated values: a) the dynamic modulus of elasticity $E_{d}$, b) the compressive strength $f_{\text {cube }}$ fibrosand-concrete 


\section{Podsumowanie}

1. Metoda indukcji elektromagnetycznej wraz z metodą opartą na prędkości propagacji fali ultradźwiękowej mogą być stosowane do identyfikacji cech drobnokruszywowego betonu zbrojonego włóknami stalowymi.
2. Zaproponowane równania regresji umożliwią nieniszczącą identyfikację cech drobnokruszywowego betonu ze zbrojeniem rozproszonym. Zależności te mogą być także przydatne do określenia cech innych materiałów podobnych do badanych pod względem składu mieszanki i rodzaju włókna.

\section{Literatura}

[1] B.R. Maidl: Steel Fibre Reinforced Concrete; Ernst \& Sohn, Berlin 1995.

[2] W. Głodkowska, J. Kobaka: Zastosowanie piasków odpadowych do wykonywania posadzek przemysłowych; Rocznik Ochrony Środowiska, 2009 (tom 11).

[3] A. Neville: Właściwości betonu; Polski Cement, Kraków 2000.

[4] L. Runkiewicz: Badania konstrukcji żelbetowych. Diagnostyka techniczna; Biuro GAMMA, Warszawa 2002.
[5] J. Hoła, K. Schabowicz: Nondestructive elastic-wave tests of posttensioned concrete girders in road bridge; 17 th WorldConference on Nondestructive Testing, e-Journal of Nondestructive Testing \& Ultrasonics, vol. 13, nr. 11., Shanghai 2008.

[6] A. Śliwiński: Ultradźwięki i ich zastosowania; WNT, Warszawa 2001.

[7] V.M. Malhorta, N.J. Carino (editors): Handbook on nondestructive testing of concrete; CRC Press, London, New York, Washington DC 2004.

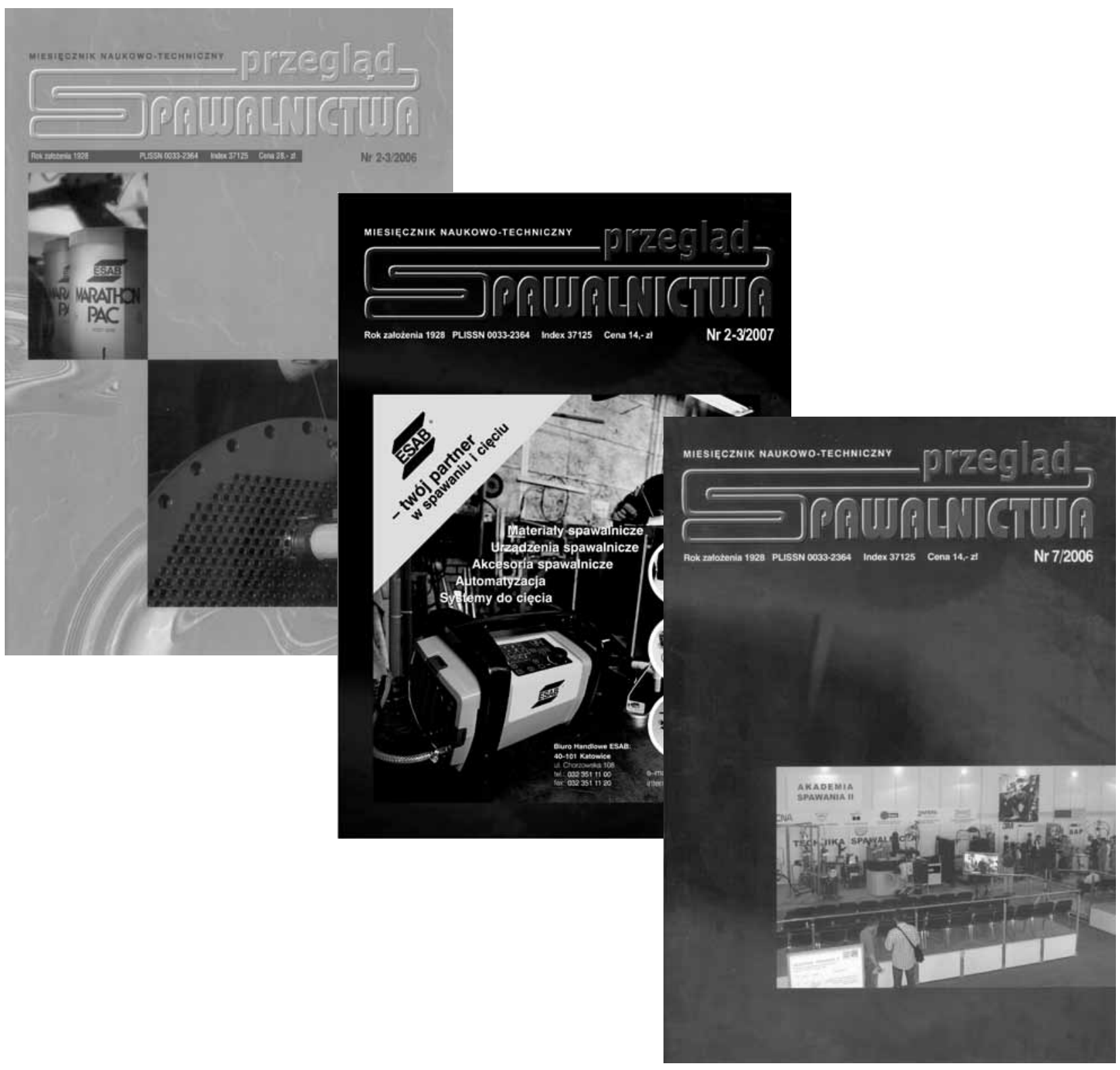

